\title{
STRUCTURAL MODELLING AND NUMERICAL ANALYSIS OF THE PALACE OF SPORTS OF MEXICO CITY
}

\section{HIRAM BADILLO-ALMARAZ ${ }^{*}$, AGUSTÍN ORDUÑ ${ }^{2}$, SERGIO G. DE LA ROSA ${ }^{1}$, GEORGIA A. GONZÁLEZ ${ }^{3}$ AND GUILLERMO M. ROEDER ${ }^{2}$}

\author{
${ }^{1}$ Civil Engineering Department \\ Universidad Autónoma de Zacatecas - UAZ \\ Av. R. López Velarde No. 801, 98060 Zacatecas, México \\ e-mail: *hbadillo.civil@uaz.edu.mx, sgdelarosa@uaz.edu.mx, www.uaz.edu.mx \\ ${ }^{2}$ Civil Engineering School \\ Universidad de Colima -UCOL \\ Km 9, Colima-Coquimatlan road, 28400 Colima, México \\ e-mail: aord@ucol.mx, groederc@ucol.mx,www.ucol.mx \\ ${ }^{3}$ Doctoral Program of Development Studies \\ Universidad Autónoma de Zacatecas - UAZ \\ Av. Preparatoria S/N, 98065 Zacatecas, México \\ e-mail: georgi_ara@hotmail.com
}

Keywords: Historical Structure, Palace of Sports, Numerical Modelling, Finite Element Analysis

\begin{abstract}
The palace of sports represents in many ways the masterpiece from the urbanarchitectural legacy that was created for the XIX Olympiad in Mexico City in 1968; its uniqueness, from the architectural and structural point of view, makes it one of the most iconic buildings of the city. In this paper the structural modelling and numerical analysis of this iconic building of the Mexican architecture of the second part of the XX century is presented. The numerical modelling is achieved by means of a $3 D$ finite element model in order to obtain preliminary results in terms of dynamic properties and linear and non-linear response of structural elements when subjected to gravity loads. Natural periods of the modes with high participating mass obtained on the numerical model are in well agreement to those of other structures with similar configurations. Nonlinear results show that the structure has a large safety factor under gravitational loads. Finally, recommendations about the improvements that can be applied on the actual FEM model are given based on the results obtained in order to give a better assessment to identify risk scenarios and to prevent them to occur on such iconic structure.
\end{abstract}

\section{INTRODUCTION}

From the urban-architectural legacy constructed for the XIX Olympiad in Mexico City in 
1968, one of the most outstanding buildings that were projected for the event is the Palace of Sports, designed by the acclaimed architect Felix Candela in collaboration with architects Enrique Castañeda and Alfonso Peyrí [1]. The building has special features that combine architectural design, structural engineering, urban art, city landscape and cultural identity that made it achieve a value closest to cultural symbolism rather than the simple physical place used for sporting or public events [2].

\subsection{Social, cultural and historical context}

The year of 1968 in Mexico has been tied to two indissoluble events: a student movement that ended tragically and the XIX Olympic Games. Both events were inserted into a society that struggled to move towards modernity; nevertheless, these events, so far from each other, transformed an entire nation [3].

The sixties represent a period of permanent growing in economic, demographic, and urban terms, to such degree that the Mexican government tried to gain visibility for the country in the international context [4]. Hence, it was essential that México radiated not only through the sporting event but also through culture and art; therefore, the interest to realize a cultural Olympiad at the same time that the games were taking place. According to Pedro Ramírez Vázquez, president of the Olympic Committee, it was necessary to "carry on to everyone the true image of Mexico" [5]. Besides, it would be the first time that the Games would be broadcasted in color television.

The idea of the Mrexican
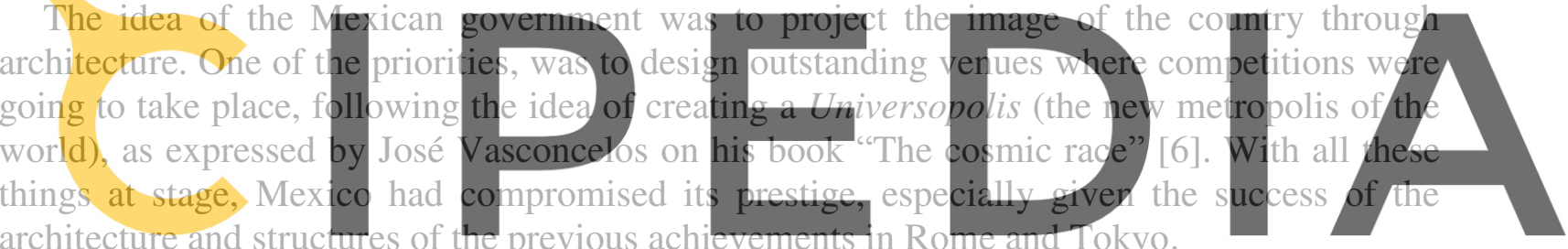

Several venues were constructed or upgraded to host the different Olympic disciplines,

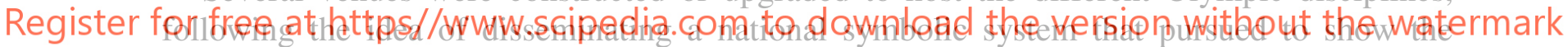

strength of the government whereas trying to renew the image of Mexico [7]; among these were the Olympic stadium, the Mexican Olympic sports center, the Olympic pool and gymnasium, the Olympic velodrome, the Olympic Village, among others. However, among all the facilities built, the Palace of Sports outstands from the rest because of its uniqueness in terms of design and aesthetics. According to several renowned architects, it represents the masterpiece and the greatest exaltation to the monumentality of that period [8].

The Palace of Sports, beyond its qualities in design and construction, is considered the geosymbol of the XIX Olympics because works like this not only transcend temporally and spatially but even could give cultural identity to a whole nation.

\section{DESCRIPTION OF THE STRUCTURE}

\subsection{Architectural aspects}

The general structure of the building was considered, from the project phase, as the dominant element of the composition, and the determinant factor of its spatial plastic sense [9]. It was projected to achieve an extraordinary design form, far from puerile and ordinary 
structures, that could result fascinating from any point of view: exterior and interior, at the pedestrian level and even from the aerial point of view [10].

According to Candela and his collaborators, the constructive solution should be completely realistic, that is, the structure had to be simple and easy to analyze and build, but above all, it would need to agree with the scale. Although the Palace of Sports of Candela, has a clear influence from Pier Luigi Nervi's Palazzo and Palazzetto of Sports, built for the 1960 Summer Olympics in Rome [11], the aforementioned considerations eliminated any chance of applying a concrete shell as roof solution for the Palace of Sports; besides, the building had to meet with the objectives marked by the organizing committee that established that the design proposals should be outstanding but feasible economically.

Due to the low ground resistance of the site, designers decided to adopt spherical dome with an approximate overall area of $27,171 \mathrm{~m}^{2}$ with a light metal structure $\left(60 \mathrm{~kg} / \mathrm{m}^{2}\right.$ approximately), where the trusses worked basically under axial compression, which makes possible to eliminate the secondary elements.

The supporting structure consists of an almost orthogonal grid of steel trusses with a constant height of $5 \mathrm{~m}$, arranged according to maximum circles of a sphere with and angle of separation of $8^{\circ}$ approximately. In Figure 1 an aerial view of the structure is presented. The spherical cover is limited by four maximum circles and divided into 121 squares, whose sides vary from 13 to $10 \mathrm{~m}$. The trusses consist of a central element working under compression, formed by rhombuses, triangulated by radial braces. The upper and lower chords work under tension forces to take positive and negative moments. The central arches have 132 m of span.

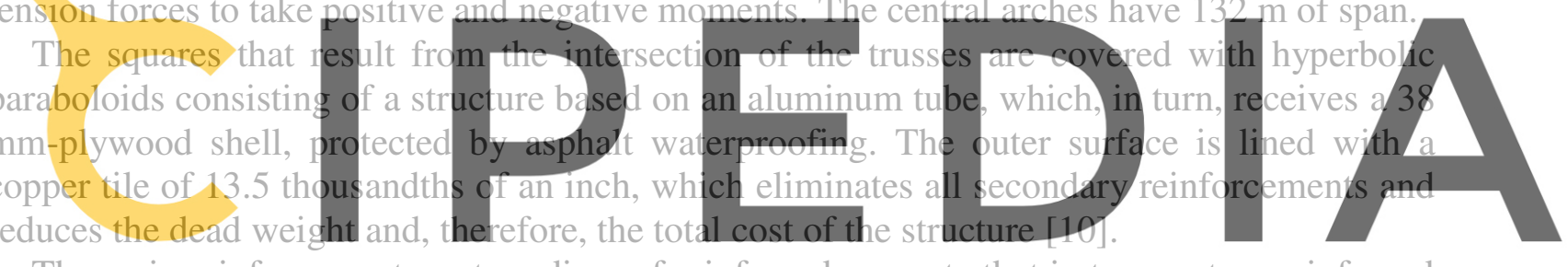

The main reinforcements rest on dices of reinforced concrete that in turn rest on reinforced

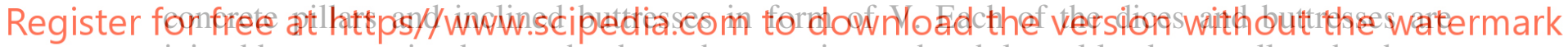
joined by connection beams that have the capacity to absorb lateral loads as well as the thrust of the arches.

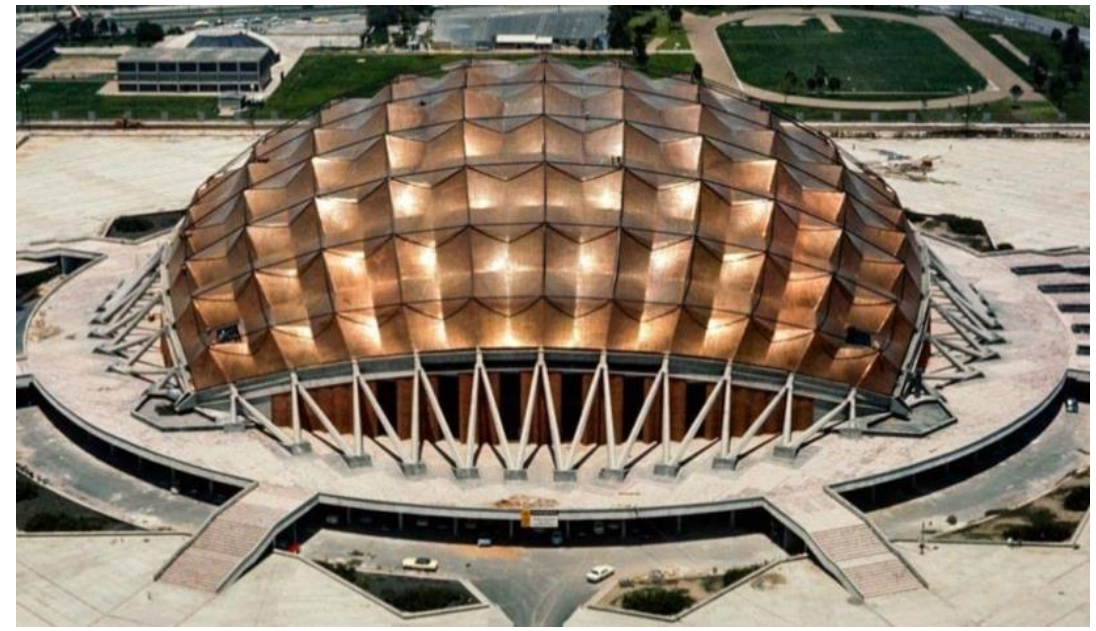

Figure 1: Aerial view of the Palace of Sports 


\subsection{Structural configuration}

The roof of the Palace of Sports is supported by two sets of circular arches that form a spherical cap of approximately square plan, with an approximate area of $13,700 \mathrm{~m}^{2}$ and without any intermediate support. The central axes of the arches are two families of meridians of a sphere of $92.6 \mathrm{~m}$ in diameter whose polar axes contained in the same horizontal plane are mutually orthogonal. Figure 2 presents details of the structural configuration of the roof. The structure is limited by four inclined planes that form a dihedral angle of $45^{\circ} 28^{\prime}$ with the two vertical planes of symmetry, in which the polar axes are contained. Each family is composed of 11 arcs separated from each other by varying distances, between 10 and $13 \mathrm{~m}$, so that the grid obtained from the two sets of arches gives as a result areas approximately squared of 12 $\times 12 \mathrm{~m}$ on average, on which hyperbolic paraboloids made with aluminum tubes supported on the main arches have been placed, and on which the roof itself rests, which is formed by plywood and copper foil as mentioned previously [12].

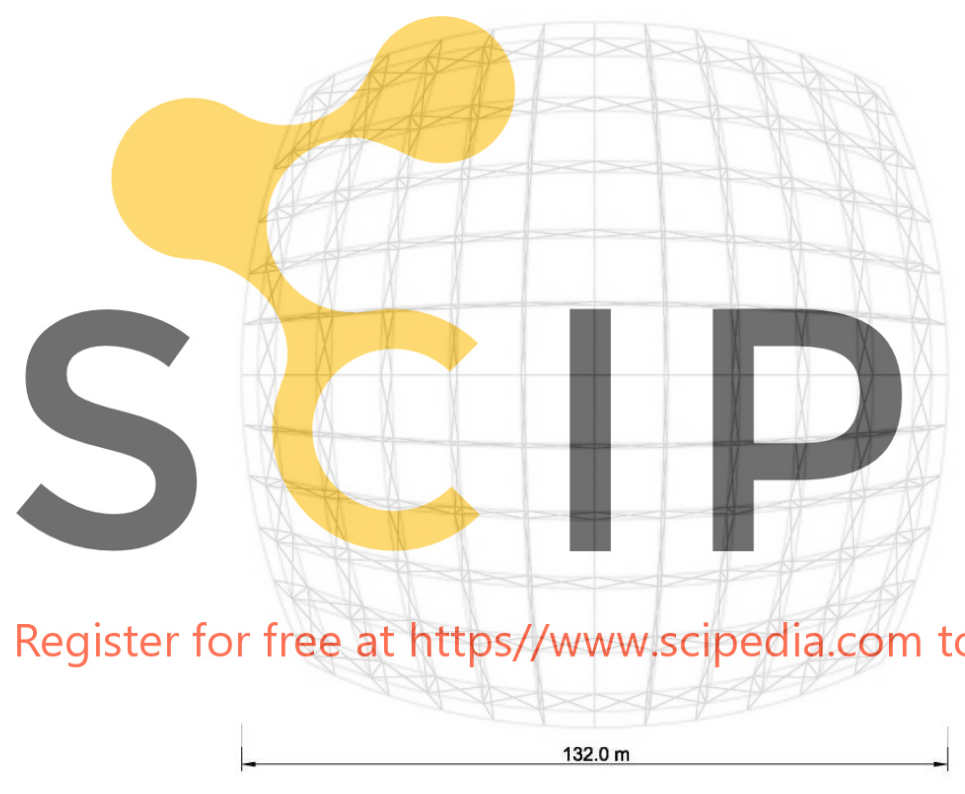

a) Plan view of the roof structure

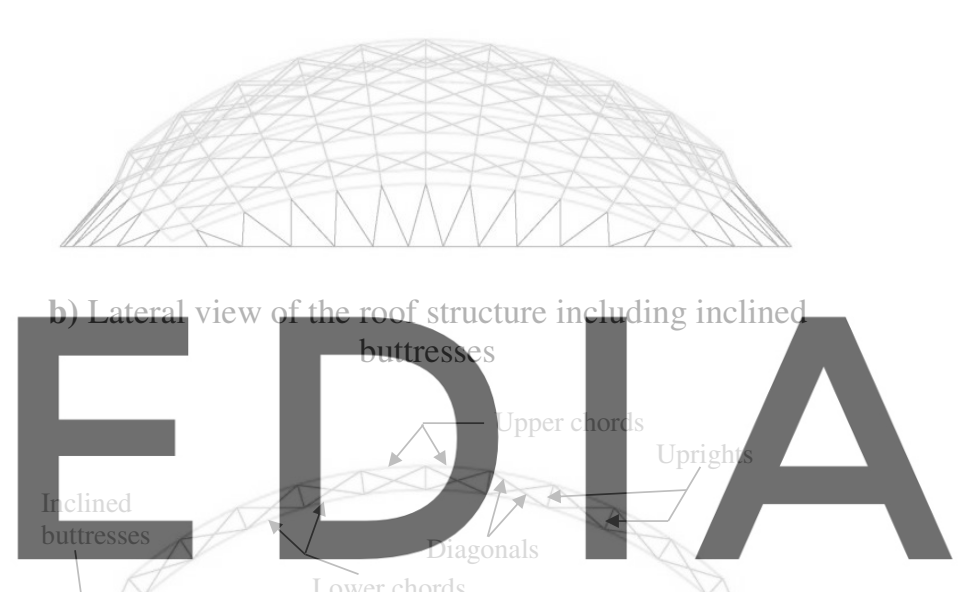

downtoad the version without the watermark

c) Geometrical representation of the central arch including inclined buttresses and pillars

Figure 2: Geometry of the roof structure

The arches have a constant height of $5 \mathrm{~m}$ measured between the axes of the chords over the entire length, except on the end panels, since they are articulated to the concrete structure that receive them. In Figure 2c, one of the 22 arches that support the roof is shown schematically.

The diagonals were designed as compressed elements to withstand almost all of the normal forces caused by permanent vertical loads, while the chords of the trusses had as basic objective to give the arch the ability to withstand the bending moments produced by wind loads, asymmetric vertical loads, differential settlements, etc.

The analysis of the roof structure was carried out by the renowned structural engineer Oscar de Buen, considering the structure as an arc lattice, formed by 11 elements in each direction, rigidly joined together at their intersections. A structure with 121 knots was 
obtained, with a high degree of hyperstaticity. Two simultaneous analyzes were made, using in one of them the method of flexibilities and in the other the stiffness method. In both cases, the effects on the deformations of the normal forces and the bending moments were taken into account. Torsional stiffness of the arches was disregarded, which in addition to introducing notable simplifications in the analysis, is fully justified in structures of this type [12]. Computers were mainly used in the following aspects: structural analysis of the roof, obtaining the detailed geometry of the roof and structural analysis of the ring that receives the arches [13].

The material used to build the structure was A36 steel, with a yield limit of $250 \mathrm{MPa}$, except for the tubes that form the chords of the arches, which were made of ASTM A120 steel, with a yield limit is $240 \mathrm{MPa}$. The diagonals and the uprights are sections $\mathrm{H}$ and I formed by three plates welded together. All the joints of the structure were welded together as well.

The profiles used were: circular tube of $21.9 \mathrm{~cm}$ of outer diameter, ID 30, thickness 0.70 $\mathrm{cm}$, for the upper and lower chords; section $\mathrm{H}$ with flanges of $30 \mathrm{~cm}$ of width and $1.6 \mathrm{~cm}$ of thickness and web of $30 \mathrm{~cm}$ by $1.27 \mathrm{~cm}$ for the diagonals; section I with flanges of $15 \mathrm{~cm}$ of width and $1.9 \mathrm{~cm}$ of thickness and web of $30 \mathrm{~cm}$ by $1.27 \mathrm{~cm}$ for the uprights.

\section{STRUCTURAL MODELLING}

\subsection{Graphicall model}

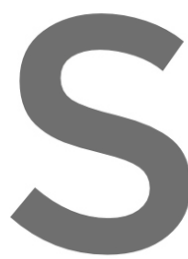

The division of sph reticular structures. Whe modeling of the Palade order to divide it into give the initial form of the reticular structure
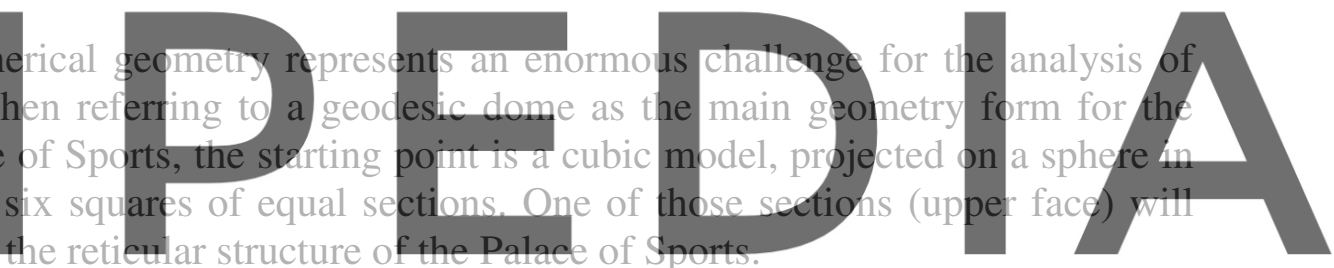

Register for free at https//www.scipedia.com to download the version without the watermark

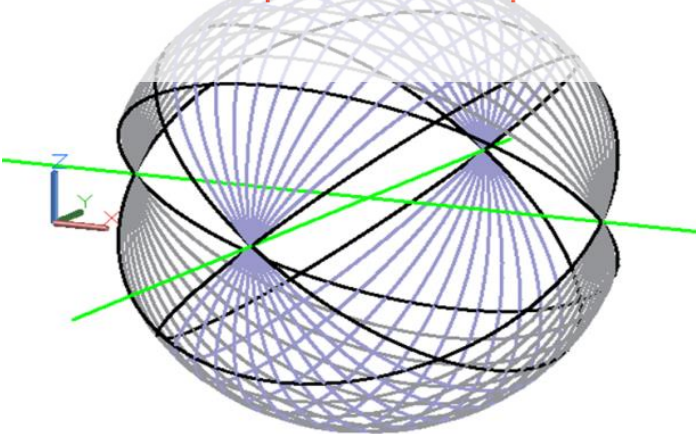

a) Central axes which work as boundaries of the guide arches

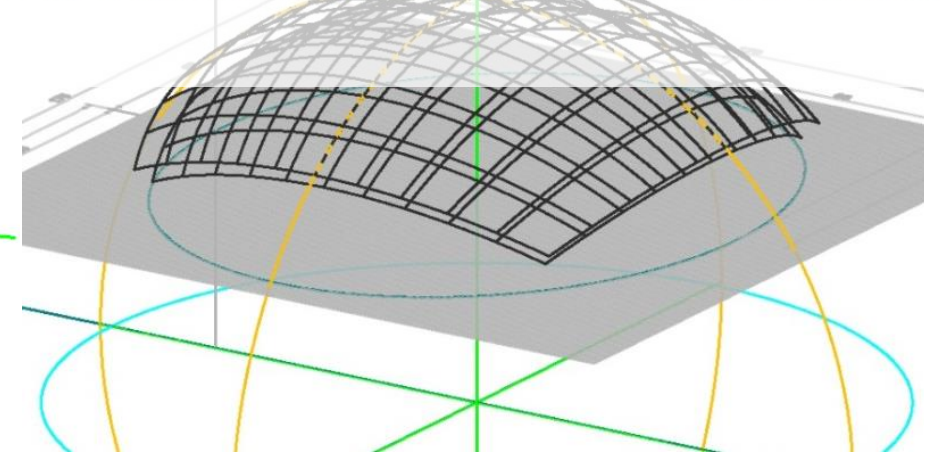

b) Main grid generated through maximum circles for the internal and external faces

Figure 3: Graphic development of the roof structure

Subsequently, guide arches (maximum circles) will be distributed with spacing with regular revolution angles and fixed to two axes perpendicular to each other (passing from end 
to end of the sphere and through the geometric center of it), until a grid of 22 arcs (11 on each direction) is generated as shown in Figure 3a; this will be the main and generating structure of all subsequent geometry. The angle of rotation in which the 11 arches are distributed to generate the grid is $8^{\circ} 16^{\prime}$ giving a total measurement of $82^{\circ} 40^{\prime}$ between the last and first arch; this causes that all the trusses of each arch will have a different inclination, i.e. none will be parallel. The radial reinforcements are 5 meters high between the family of internal arches and that of the external ones. In Figure $3 \mathrm{~b}$ the main grid generated through maximum circles for the inner and outer faces of the structure $(90.1 \mathrm{~m}$ and $95.1 \mathrm{~m}$ of diameter) with $5 \mathrm{~m}$ of separation between them is presented.

To define the position of the buttresses and the supports of each arch, the geometry between the grid of arcs will be further prolonged in order to obtain the crossing points with the horizontal plane that will indicate the location of the connecting points of the rooftop cover with the buttresses and of the buttresses with the ground. This grid will need another pair of guide arches on each edge, for the tracing of the supports that will be a transition section between the metal structure and the concrete supports. The buttresses locations are defined as a continuation of the initial geometry of the geodesic dome. Furthermore, uprights and diagonals that connect each of the edges of the uprights are included.

Once the main structure for the dome and buttresses is finished, the same arc geometry will be used for the generation of a third grid that will support the closing substructure of the dome. This intermediate grid passes through each quadrant of the main structure at its

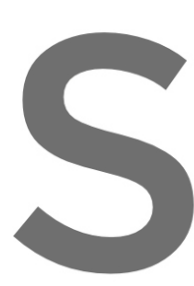
midpoints, as it will

\section{pyramids of the roof}
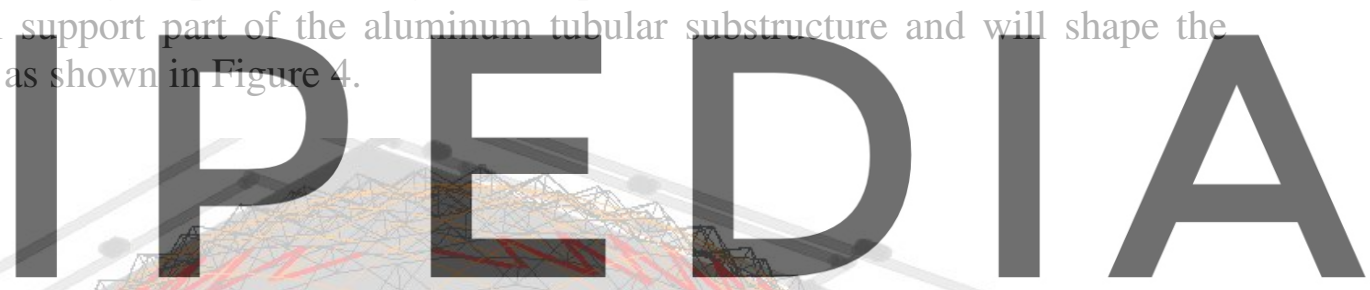

Register for free at https//www.scipedia.com to download the version without the watermark

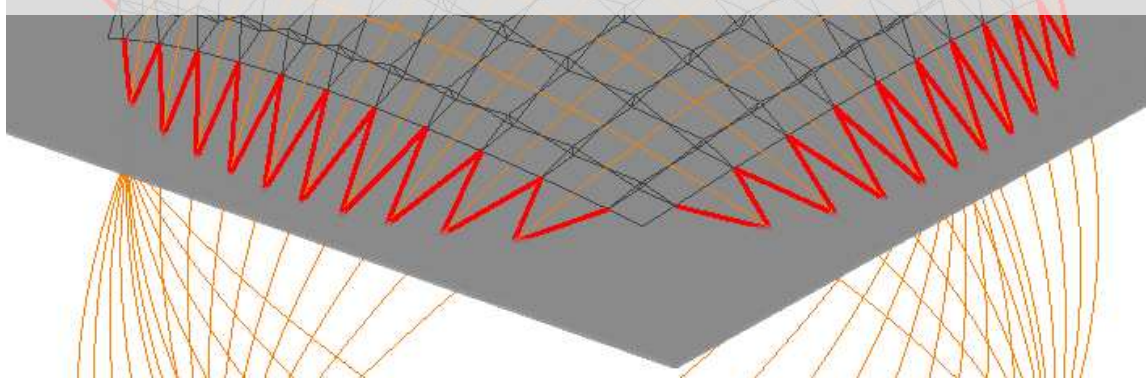

Figure 4: Descriptive geometry of the main structural elements of the Palace of Sports

The rooftop cover of the dome is generated from fragments of hyperbolic paraboloids inserted in the quadrilaterals generated after the subdivision of the dome. Since the hyperbolic paraboloids consist of ruled surfaces, the assembly process was greatly simplified, since the whole cover could be carried out by straight elements without curvature. The characteristic copper finish on the dome sits on wooden boards that are placed on a triangulated grid of 
aluminum tubes. The gaps that are formed by the intersection of the grids are approximately $12 \times 12 \mathrm{~m}$ and were covered with four hyperbolic paraboloid panels based on a three-way grid better known as the triodetic system, which, in turn, receives the plywood cover that forms the dome rooftop enclosure.

The enclosure modules do not hide the structure of spherical arches since they are located between the two concentric spheres. The intersection point of four hyperbolic paraboloid fragments links the metal arches of the dome, making contact with the upper and lower arches alternatively. In this way, the main structure can be appreciated from the inside and from the outside. On Figure 5a, a projection of the aluminum grid over the upper diagonals of the arches is presented (bottom diagonals not shown on the figure). Figure $5 \mathrm{~b}$ presents a lateral and corner view of the completed graphical model. The graphical model was entirely developed using the software AutoCAD.

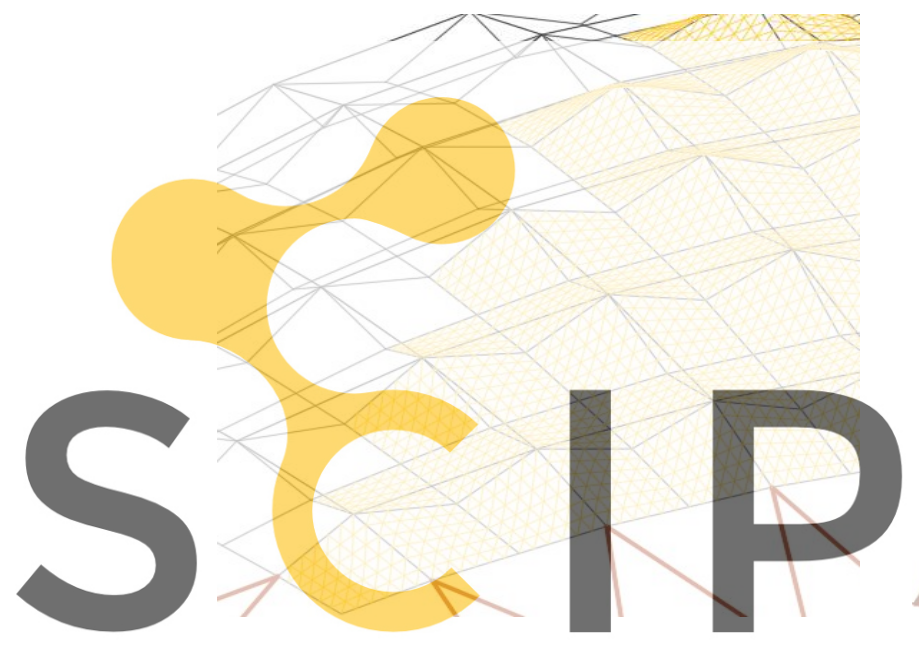

a) Projection of the aluminum grid over the
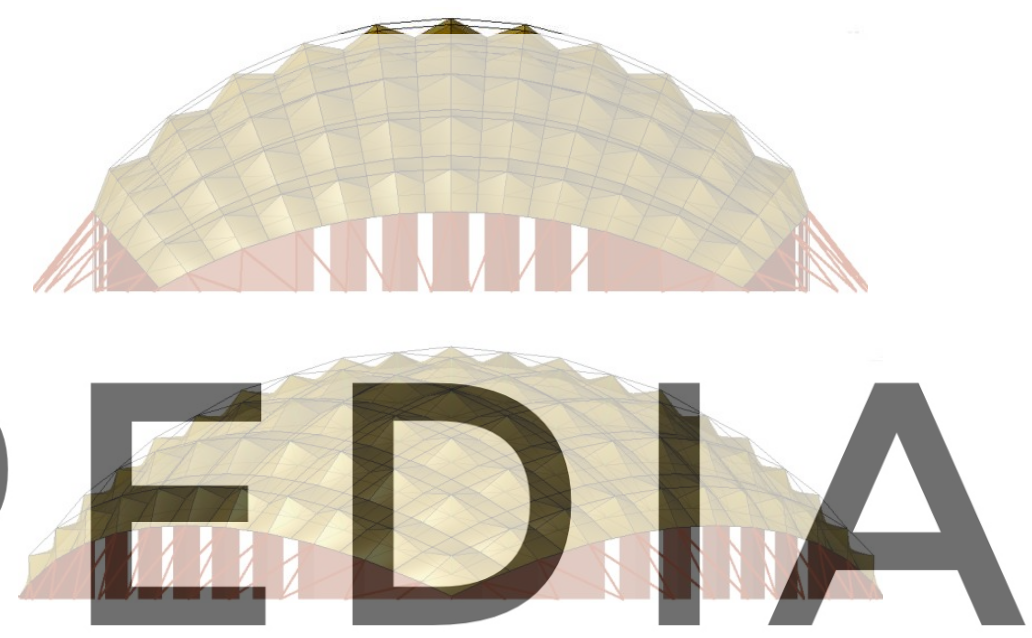

b) Lateral and corner view of the completed model

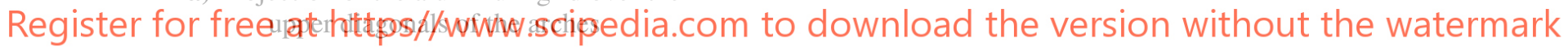

Figure 5: Graphical model of the Palace of Sports

\subsection{Finite element model}

In order to analyze the structural behavior of the Palace of Sports a Finite Element Method (FEM) model was developed based on the graphical model described previously. The model includes the following types of materials: steel, concrete, aluminum and a rooftop cover composite element that comprises the plywood and the cooper foil altogether.

Steel elements are assigned the upper and lower chords (circular tubes), uprights (sections I) and diagonals (sections $\mathrm{H}$ ) of the trusses; sections $\mathrm{H}$ are also used on the boundary elements that define the perimeter of the roof structure. Concrete elements are assigned to the vertical reinforced concrete pillars and inclined buttresses in form of $\mathrm{V}$ and on the walls of the perimeter. Aluminum elements are assigned to the contour of the grid of the triodetic system (circular tubes of $95.25 \mathrm{~mm}$ of diameter and thickness of $4.1 \mathrm{~mm}$ ) and to elements of the triodetic system itself (circular tubes of $47.625 \mathrm{~mm}$ of diameter and thickness of $2.032 \mathrm{~mm}$ ). The plywood and the cooper foil composite are assigned to the elements that serve as rooftop cover of the structure. Table 1 shows the mechanical properties of each the materials used in 
the numerical analyses. It is important to mention that the density of the rooftop cover composite is modified in order to include, together with the self-mass of the composite, an additional mass of $20 \mathrm{~kg} / \mathrm{m}^{2}$ for installations and another of $20 \mathrm{~kg} / \mathrm{m}^{2}$ for live load.

Table 1: Mechanical properties of the materials used in the numerical analyses

\begin{tabular}{ccccc}
\hline Material & $\begin{array}{c}\text { Young's modulus } \\
(\mathrm{GPa})\end{array}$ & $\begin{array}{c}\text { Poisson } \\
\text { relation }\end{array}$ & $\begin{array}{c}\text { Yield stress } \\
(\mathrm{MPa})\end{array}$ & $\begin{array}{c}\text { Density } \\
\left(\mathrm{kg} / \mathrm{m}^{3}\right)\end{array}$ \\
\hline STEEL & 206 & 0.28 & 250 & 7800 \\
\hline CONCRETE & 21.7 & 0.15 & 24 & 2400 \\
\hline ALUMINUM & 68.6 & 0.33 & 50 & 2700 \\
\hline $\begin{array}{c}\text { ROOFTOP COVER } \\
\text { COMPOSITE }\end{array}$ & 10 & 0.15 & N/A & 4740 \\
\hline
\end{tabular}

The model was analyzed with the FEM software DIANA-FEA [14]. For the modelling of the vertical reinforced concrete pillars and inclined buttresses, the steel, and aluminum elements a two-node, three-dimensional class-III beam element was used. Meanwhile for the walls of the perimeter and for the rooftop cover composite, four-node quadrilateral isoparametric curved shell elements based on linear interpolation and Gauss integration over the element area were used in combination with three-node triangular isoparametric curved shell elements based on linear interpolation and area integration. The model included 22,199 nodes and 75,062 elements. The bounarry conditions of the F fully constrained on the since in the actual structure they are connected foundation of friction and point bearing pile elements extruded and with the corresponding
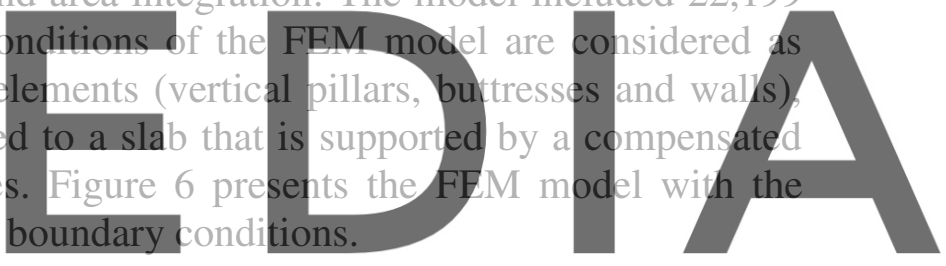

Register for free at https//www.scipedia.com to download the version without the watermark

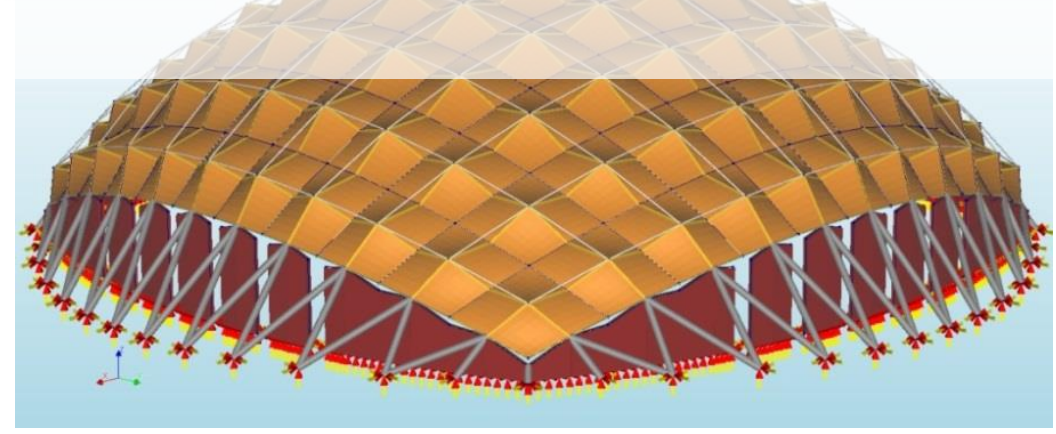

Figure 6: FEM model with extruded elements and boundary conditions

\section{RESULTS}

The FEM model of the Sports Palace was subjected to a modal analysis in order to obtain the main dynamic properties of the structure. Furthermore, it was also analyzed considering the action of vertical loads taking into account the nonlinear behavior of the steel and aluminum elements of the roof structure. 


\subsection{Modal Analysis}

In order to validate the FEM model, the first 40 natural modes were calculated. Figure 7 shows the six first modal shapes. Color scales represent vertical displacements and go from red for maximum upward displacements, to blue for maximum downward displacements. On this figure it is interesting to observe that, due to the structural symmetry, there are pairs of modes that have equal periods and have essentially the same shape but rotated $90^{\circ}$; for instance, modes 2 and 3, on one hand, and modes, 5 and 6, on the other hand.

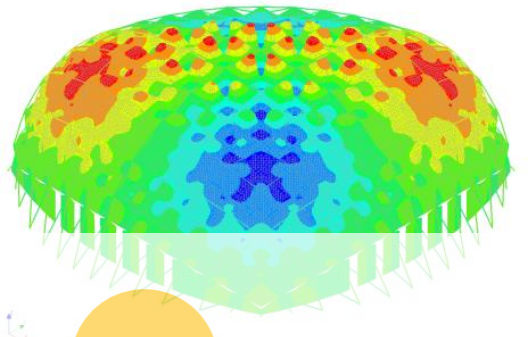

a) Modal shape 1

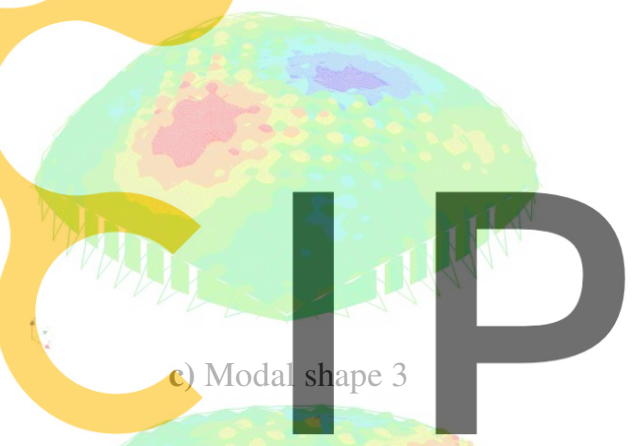

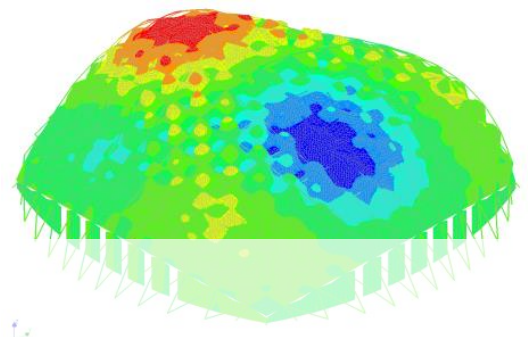

b) Modal shape 2

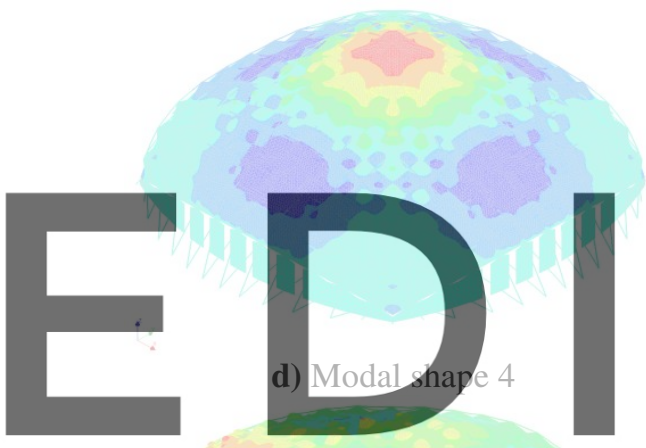

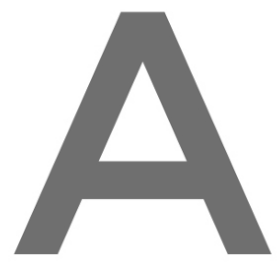

Register for free at https//www.scipedia.com to download the version without the watermark

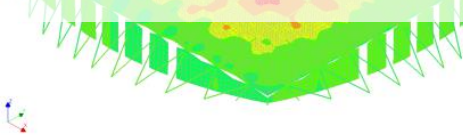

e) Modal shape 5

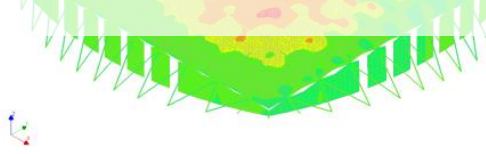

f) Modal shape 6

Figure 7: First six modal shapes of the Palace of Sports

Table 2: Natural periods of the first ten modes

\begin{tabular}{cccc}
\hline Mode & $\begin{array}{c}\text { Period } \\
(\mathrm{s})\end{array}$ & Mode & $\begin{array}{c}\text { Period } \\
(\mathrm{s})\end{array}$ \\
\hline 1 & 0.759 & 6 & 0.357 \\
2 & 0.549 & 7 & 0.333 \\
3 & 0.549 & 8 & 0.323 \\
4 & 0.459 & 9 & 0.314 \\
5 & 0.357 & 10 & 0.309 \\
\hline
\end{tabular}


Table 2 presents the periods of the first ten modes. The first natural period seems to be very small for a large span structure; nevertheless, it must be taken into account that the roof has a light weight. Similar structures with spatial frames covering large spans present natural vibration periods similar to the ones obtained in this study [15]. The dynamic behavior of the Palace of Sports reflects the structural soundness and stiffness of the building.

\subsection{Nonlinear Analysis with vertical Loads}

A nonlinear analysis under gravitational loads is useful to assess the safety of the structure for this action. The dead loads applied are the structure self-weight plus a load of $0.2 \mathrm{kN} / \mathrm{m}^{2}$ accounting for installations and other objects hanging from the roof. Additionally, a live load of $0.2 \mathrm{kN} / \mathrm{m}^{2}$ is also included in the analysis. The load factor affects both, the dead and live loads. The analysis takes into account only the nonlinear effects of steel and aluminum elements, according to the yield stresses reported at Table 1.

For a unitary load factor, the center of the structure has a displacement of $36 \mathrm{~mm}$; this represents only a $3700^{\text {th }}$ of the span. Figure $8 \mathrm{a}$ presents the vertical displacements for this condition; figure $8 \mathrm{~b}$ presents the Von Mises stresses [14]; and figure 8c shows the reactions at one side of the structure. From figure $8 \mathrm{~b}$ it is observed that the maximum stress at steel elements is $85 \mathrm{MPa}$, which represents the $34 \%$ of the yield stress. Meanwhile, in Figure 8c, it is observed that the inclined buttresses take most of the load that is transmitted from the roof structure to the ground.
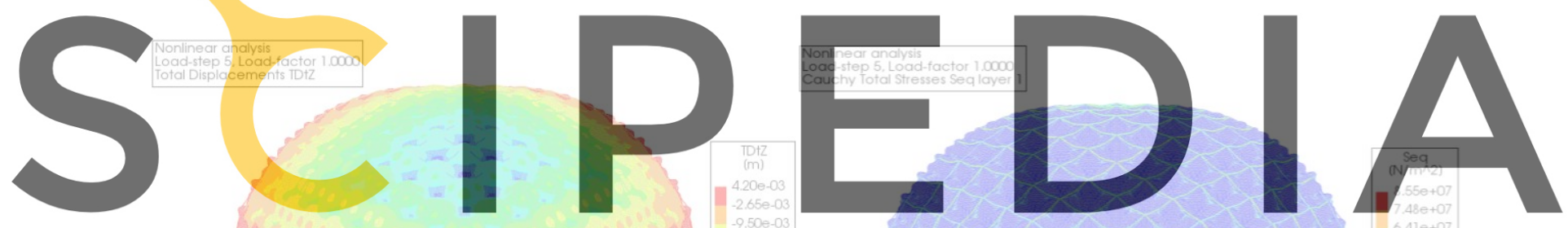

Register for free at https//www.scipedia.com to download the version without the watermark

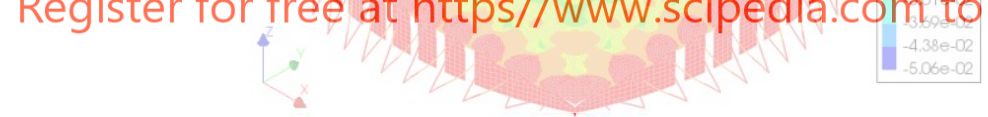

a) Vertical displacements
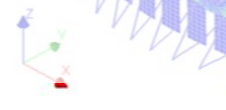

b) Von Mises stresses

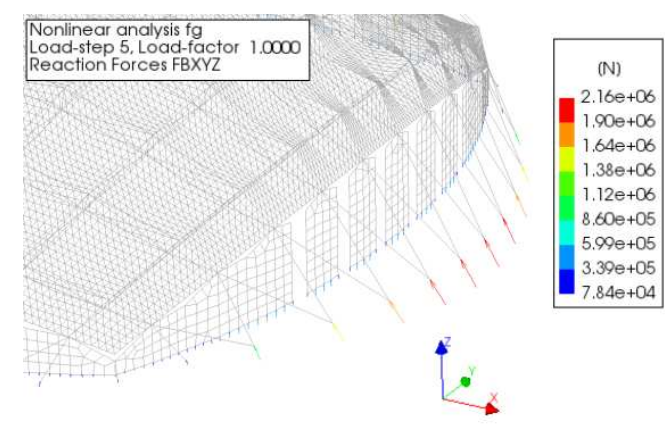

c) Reactions

Figure 8: Behavior under unitary load factor 
Figure 9 presents the load factor vs. vertical displacement at the center of the dome. This figure shows that the roof structure behaves linearly until 4 times the loads considered. Also, its maximum capacity is higher than 4.8 times the vertical loads.

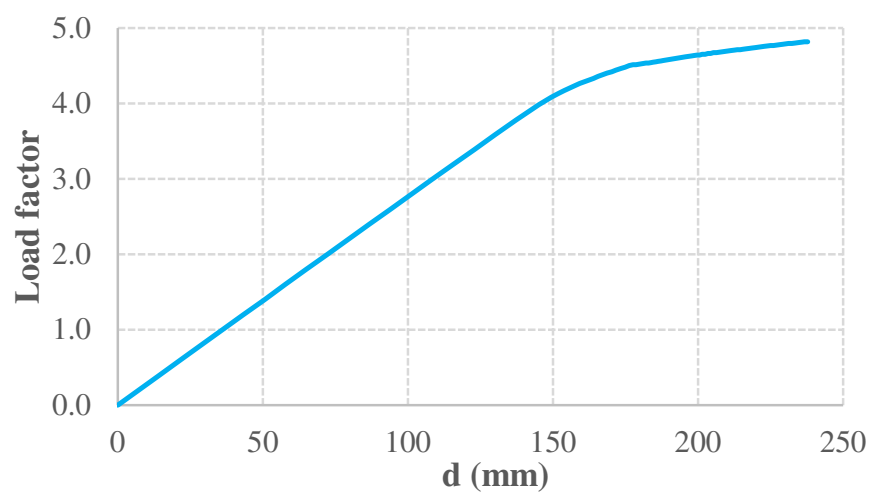

Figure 9: Load-displacement graph for nonlinear analysis

Figure 10 shows the vertical displacements and Von Mises stresses at the last step of the nonlinear analysis for a load factor of 4.8. Figure 10a shows that a maximum vertical displacement downwards of $238 \mathrm{~mm}$ has been reached on the center of the rooftop, which represents a 560th of the span; meanwhile Figure 10b illustrates that steel elements have reached their yield stress.

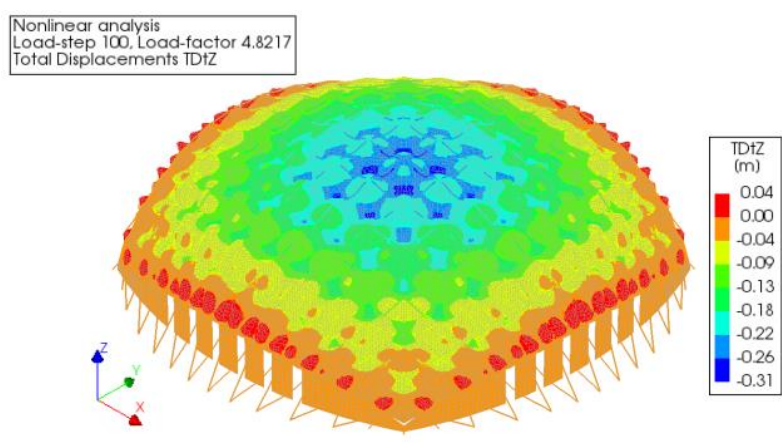

a) Vertical displacements

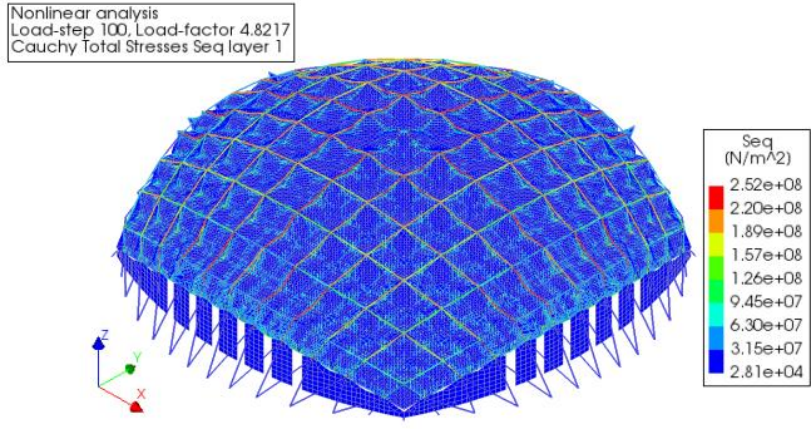

b) Von Mises stresses

Figure 10: Behavior under load factor of 4.8

\section{CONCLUSIONS}

This paper presents a brief review of the historical architectural and structural relevance of the iconic Palace of Sports of Mexico City. The paper also presents the development of geometrical and FEM models. It is important to point out that this is the first advanced structural analysis of this construction since it was designed with rudimentary computational tools. The results in terms of natural modes indicate that this preliminary model is a good approximation of the behavior of the real structure. The dynamic behavior of the Palace of Sports reflects the stiffness and structural soundness of the building. The nonlinear analysis under gravitational loads shows that the structure has a large safety factor for this action. 
Tasks to perform in future stages of this project include the determination in situ of the natural vibration frequencies of the first natural modes of the structure in order to validate or adjust the properties of the FEM model and performing nonlinear analysis of the model under gravitational loads taking into account mechanical and geometric non-linearities, seismic and wind actions in order to give a safety assessment to identify risk scenarios and to prevent them to occur on such iconic structure.

Acknowledgements. The authors would like to thank to the Public Bureau of Education (Secretaría de Educación Publica) of the Mexican Government for the funds provided to publish this paper through the project "Fortalecimiento de la calidad académica de los programas de licenciatura de la DES de Ingeniería". This support is greatly appreciated.

\section{REFERENCES}

[1] Candela, F., Castañeda E. and Peyri A. Palacio de los Deportes. Arquitectura (1968) 1016:10-13.

[2] García, J.A. and Gallegos, B.M. Patrimonio de la XIX Olimpiada "México 68": los retos para su preservación. Revista Gremium (2017) 4-07:99-114.

[3] Trejo, R. Esos fueron los días. Cultura social, creatividad y libertad en el México de 1968. Revista Mexicana de Ciencias Políticas y Sociales (2018) 234:153-176.

[4] Pozas, R. Los años sesenta en México: la gestación del movimiento social de 1968. Revista Mexicana de Ciencias Políticas y Sociales (2018) 234:111-132.

[5] Ramírez, P. México ante las olimpiadas. Arquitectura (1968) 10-116:2-5.

[6] Vasconcelos, J. La raza cósmica: misión de la raza iberoamericana. Espasa, (1948).

[7] Canales, A.F. La modernidad arquitectónica en México. Una mirada a través del arte y los medios impresos. Tesis Doctoral, Universidad Politécnica de Madrid, (2013).

[8] De Anda Alanís, E.X. Historia de la arquitectura mexicana. Gustavo Gili, (2019).

[9] Candela, F., Peyri A. and Castañeda E. Palacio de los Deportes. Informes de la Construcción, Consejo Superior de Investigaciones Científicas (1968) 21-205:1-7.

[10] Candela, F., Castañeda E. and Peyri A. Proyecto Arquitectónico del Palacio de los Deportes. Revista Ingeniería, Universidad Nacional Autónoma de México (1968) 37-4: 429-433.

[11] Castañeda, L. Image-Machine: Félix Candela's Palacio de los Deportes. Pidgin (2010) 8: 246-257.

[12] De Buen, O. Estructura de acero de la cubierta del palacio de los deportes. Revista Ingeniería, Universidad Nacional Autónoma de México (1968) 37-4: 456-461.

[13] Damy, J. Utilización de las computadoras electrónicas en el análisis del palacio de los deportes. Revista Ingeniería, Universidad Nacional Autónoma de México (1968) 37-4: 462-466.

[14] TNO DIANA. Finite element analysis user's manual release 10.1. DIANA FEA BV, Netherlands, (2017).

[15] Wu, J., Zhang, Y. and Geng, X. Dynamic behaviors of two large spatial structures. In: J. F. Abel and J. R. Cooke (Eds.): IASS-IACM 2008: "Spanning Nano to Mega" Computation of Shell and Spatial Structures (2008). 